\title{
THE MECHANICAL PROPERTIES OF SINGLE CRYSTALS OF PURE ICE
}

\author{
By S. J. Jones* and J. W. GLen \\ (Department of Physics, University of Birmingham, Birmingham, England)
}

\begin{abstract}
Results obtained from tensile and compressive tests on pure ice single crystals at various temperatures down to $-90^{\circ} \mathrm{C}$ are reported. At $-50^{\circ} \mathrm{C}$ tensile creep tests give a continually increasing creep rate until fracture, as observed at higher temperatures. The stress dependence of the strain-rate is discussed. Fracture stress increases with decreasing temperature. Results from constant strain-rate compressive tests are compared with theoretical curves computed from Johnston's (1962) theory of dislocation multiplication. A dislocation velocity of the order of $0.5 \times 10^{-8} \mathrm{~m} \mathrm{~s}^{-1}$ is deduced for ice at $-50^{\circ} \mathrm{C}$.
\end{abstract}

RÉsumÉ. Les propriétés mécaniques de monocristaux de glace pure. Les résultats obtenus d'essais d'élongation et de compression sur des monocristaux de glace pure à températures jusqu'à $-90^{\circ} \mathrm{C}$ sont présentés. $\mathrm{A}-50^{\circ} \mathrm{C}$ les essais de fluage par élongation donnent une vitesse de fluage croissante continue jusqu'à fracture comme on l'a observé à de plus hautes températures. La dépendance de contrainte avec la vitesse de fluage est discutée. La contrainte de fracture augmente avec la diminution de température. Les résultats d'essais de vitesse de déformation sous compression constante sont comparés aux courbes théoriques déduites de la théorie de multiplication des dislocations de Johnston ( 1962$)$. Une vitesse de dislocation de l'ordre de $0,5 \times 10^{-8} \mathrm{~m} \mathrm{~s}^{-1}$ est déduite pour la glace à $-50^{\circ} \mathrm{C}$.

Zusammenfassung. Die mechanischen Eigenschaften von Einkristallen reinen Eises. Ergebnisse von Dehnungsund Druckversuchen an Einkristallen reinen Eises bei verschiedenen Temperaturen bis zu $-90^{\circ} \mathrm{C}$ werden mitgeteilt. Bei $-50^{\circ} \mathrm{C}$ ergaben Dehnungskriechversuche eine ständig wachsende Kriechgeschwindigkeit bis zum Bruch, wie es auch bei höheren Temperaturen beobachtet worden war. Die Abhängigkeit der Spannung von der Dehnungsgeschwindigkeit wird diskutiert. Die Bruchspannung wächst mit sinkender Temperatur. Ergebnisse von Druckversuchen bei konstanter Dehnungsgeschwindigkeit werden mit theoretischen Kurven verglichen, die nach Johnstons ( 1962 ) Theorie der Versetzungsvervielfachung berechnet wurden. Für Eis bei $-50^{\circ} \mathrm{C}$ wird eine Versetzungsgeschwindigkeit in der Grössenordnung von $0,5 \times 10^{-8} \mathrm{~m} \mathrm{~s}^{-1}$ abgeleitet.

\section{INTRODUCTION}

The present authors have presented two previous papers concerned with the mechanical properties of pure ice (Glen and Jones, 1967; Jones and Glen, I968). This third paper presents further results and also summarizes the earlier results in order to present a complete account of the work done at the University of Birmingham between 1964 and 1967 . The work that was done on impure ice has been separately reported (Jones and Glen, 1969) and is not mentioned here.

The object of the experiments was to investigate the mechanical properties of ice single crystals at temperatures lower than had previously been attempted. A number of workers have conducted investigations close to the melting point, and two groups, Readey and Kingery (I964) and Higashi and others (1965), have made studies at various temperatures down to $-42^{\circ} \mathrm{C}$. The present work includes results at temperatures down to $-90^{\circ} \mathrm{C}$.

\section{Tensile Creep Tests}

The method of growth of the crystals and a description of the tensile creep apparatus have been given by Glen and Jones (1967).

\section{The glide direction}

All the results pertinent to this question were presented by Glen and Jones (1967). The conclusion reached then was that $\langle\mathrm{I} I \overline{2} \mathrm{O}\rangle$ is the glide direction in ice, a result which confirms the X-ray topographical work of Hayes and Webb (1965).

\footnotetext{
* Present address: Inland Waters Branch, Department of Energy, Mines and Resources, Ottawa, Ontario, Canada.
} 
Analysis of creep curves

Creep curves obtained at $-50^{\circ} \mathrm{C}$ are shown in Figure $\mathrm{r}$, in which the shear strain resolved on the basal plane, as defined by Schmid and Boas (1950, p. 58), is plotted as a function of time. It is of the same form as that found at higher temperatures; a continually increasing creep rate is observed with no apparent strain hardening. The shape of the curves was found by plotting the logarithm of the strain $\epsilon$ against the logarithm of the time $t$ as is done in Figure 2. In all cases the result was a straight line showing that

$$
\epsilon \propto t^{m}
$$

where $m=\mathrm{r} .5 \pm 0.2$ for shear strains between 0.3 and $4 \%$. Below $0.3 \%$ measurements of the strain were unreliable. Above $4 \%$ the apparent value of $m$ increased, possibly due to increased stress in the deformed region of the crystal, and for one crystal $m$ equalled 2.2 between shear strains of 10 and $30 \%$.

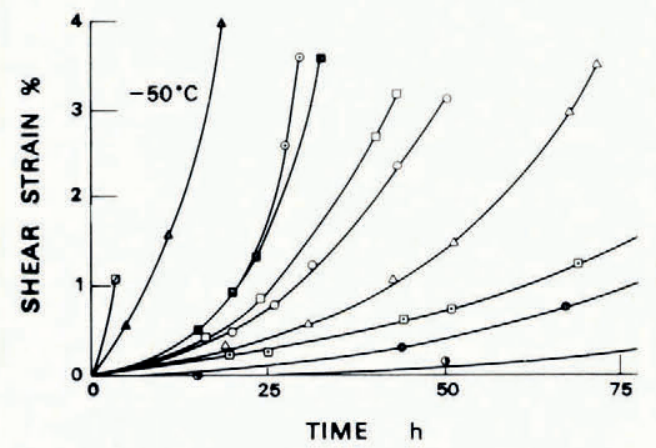

Fig. I. Creep curves of ice single crystals deformed under various stresses at $-50^{\circ} \mathrm{C}$.

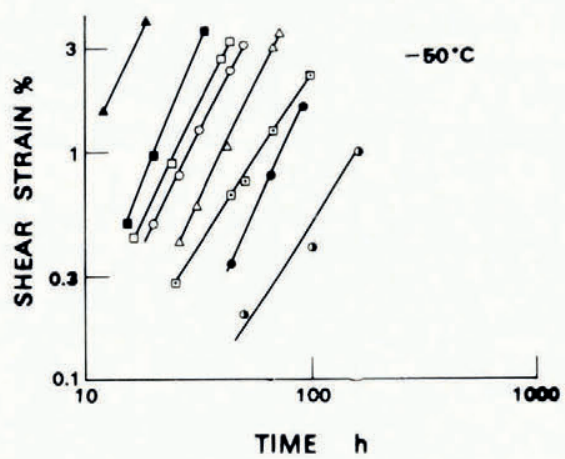

Fig. 2. Creep curves of Figure I plotted logarithmically.

Since $\epsilon \propto t^{1 \cdot 5}$, it follows that $\dot{\epsilon} \propto t^{0.5}$ and hence $\dot{\epsilon} \propto \epsilon^{\mathrm{I} / 3}$. This being so, $\dot{\epsilon} / \epsilon^{\mathrm{I} / 3}$ should be a constant for each crystal, the value of which depends on the resolved shear stress acting on the crystal. This was found to be so and since it was expected that the dependence of strainrate on stress would be a power-law type relationship, a graph of $\log \left(\dot{\epsilon} / \epsilon^{1 / 3}\right)$ against $\log \tau$ was plotted as shown in Figure 3. A straight line was fitted to these data by the method of least squares and is drawn on Figure 3 . The equation for this line is

$$
\dot{\epsilon} / \epsilon^{\mathrm{T} / 3}=\left(\tau / \tau_{0}\right)^{n}
$$


with $n=2.2 \pm 0.3$ and $\tau_{0}=\mathrm{I} 930$ bar $^{1 / 2.2}$. However, it is possible that the data would be fitted better by a non-linear curve, and to test for this, a least-squares determination of the constants in the simple parabolic type of equation

$$
\log \left(\dot{\epsilon} / \epsilon^{\mathrm{I} / 3}\right)=a+b \log \tau+c(\log \tau)^{2}
$$

was made with the help of the University of Birmingham Computer Services' KDF 9 computer. Once this had been done, the Gauss criterion, as defined by Worthing and Geffner (I943, p. 26o) was used to determine whether the linear or non-linear function was the better

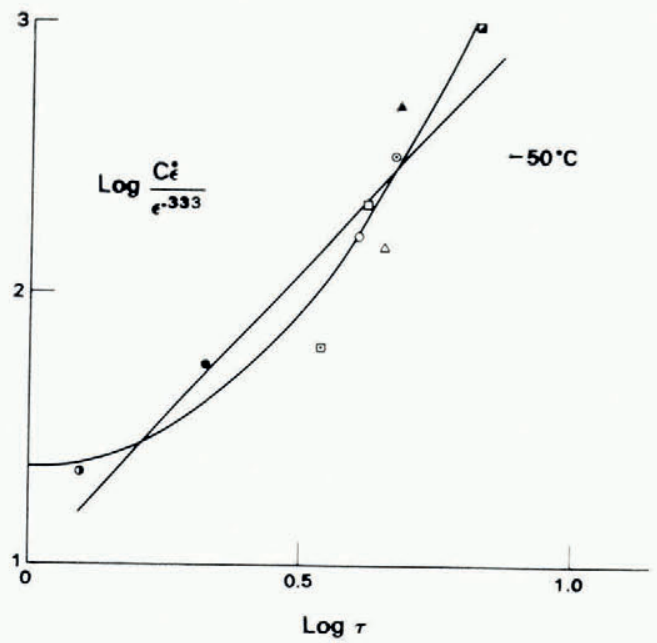

Fig. 3. The stress dependence of the strain-rate of the crystals deformed at $-50^{\circ} \mathrm{C}$.

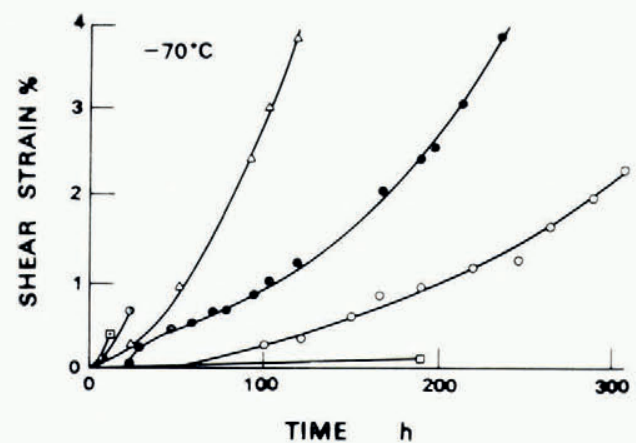

Fig. 4. Creep curves of ice single crystals deformed under various stresses at $-70^{\circ} \mathrm{C}$.

fit to the experimental data. For the data obtained at $-50^{\circ} \mathrm{C}$ (Fig. 3), the non-linear law, which is also drawn on the figure, proved to give a better fit. It is possible that the data are still better fitted with another non-linear equation, for example a circle or cubic parabola, but these were not tested since the object was primarily to show whether or not the data were randomly distributed about a straight line. Since now the slope of the curve is a function of stress, this means that in the power-law expression (Equation (2) above) $n$ varies with stress from I.o at $\tau=\mathrm{I} .6$ bar to 4 . I at $\tau=6.2$ bar. The value of $n$ reported at Sapporo (Glen and Jones, 1967 ) of $4 \pm \mathrm{I}$ is the value obtained at the higher stresses only. 
All data obtained from creep tensile tests at $-60^{\circ} \mathrm{C}$ were reported by Jones and Glen (r 968 ) and so will not be repeated here. The $-60^{\circ} \mathrm{C}$ creep curves were analysed in an identical manner to those obtained at $-50^{\circ} \mathrm{C}$ and it was again found that a parabolic term in $\log \tau$ gave a better fit to the experimental data than simply a straight line.

The creep curves obtained at $-70^{\circ} \mathrm{C}$ are shown in Figure 4 and their analysis is shown in Figures 5 and 6 . In Figure 6, a straight line of slope $n=2.3$ gave a better fit to the experimental data than the non-linear function. The results are summarized in Table I, from which it can be seen that $m$ is independent of temperature.

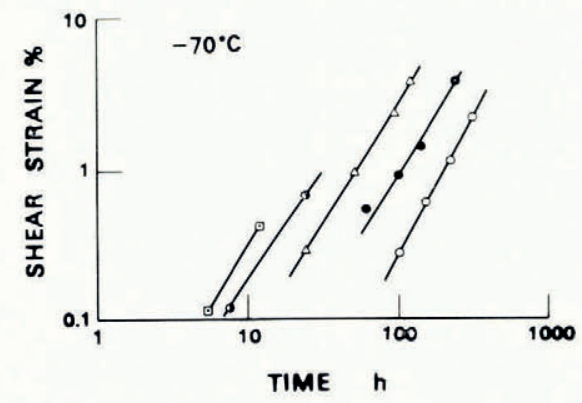

Fig. 5. Creep curves of Figure 4 plotted logarithmically.

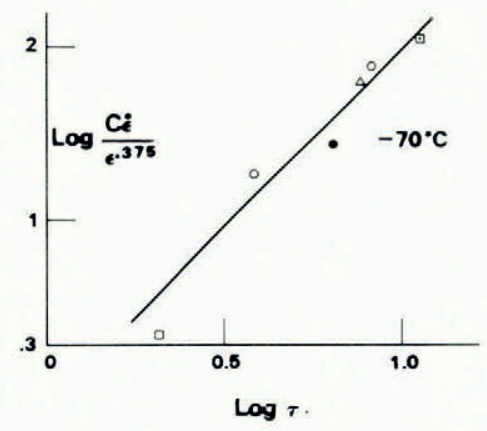

Fig. 6. The stress dependence of the strain-rate of the crystals deformed at $-70^{\circ} \mathrm{C}$.

Table I. Parameters Determined for Flow LaW

$\begin{array}{ccc}\begin{array}{c}\text { Temperature } \\ { }^{\circ} \mathrm{C}\end{array} & m & n \\ -50 & 1.5 \pm 0.2 & \text { 1 at } \mathrm{I} \text { bar } \\ -60 & 1.4 \pm 0.2 & 4 \text { at } 6 \text { bar } \\ -60 & \text { I at } 2 \text { bar } \\ -70 & 1.6 \pm 0.2 & 4 \text { at } 6 \text { bar } \\ & & 2.3\end{array}$

An attempt was made to obtain creep curves at $-90^{\circ} \mathrm{C}$ but on all occasions the crystal fractured before any significant strain could be detected. As discussed by Jones and Glen (1968), more specimens need to be tested at this temperature before it is possible to say categorically whether or not ice crystals are brittle at $-90^{\circ} \mathrm{C}$. 


\section{Activation-energy analysis}

Details of this analysis have been given by Jones and Glen (1968). It was found that between $-10^{\circ}$ and $-50^{\circ} \mathrm{C}$ the activation energy was $0.68 \pm 0.04 \mathrm{eV}(65 \pm 3 \mathrm{~kJ} / \mathrm{mol})$ and between $-50^{\circ}$ and $-90^{\circ} \mathrm{C}$ it was $0.4 \mathrm{I} \pm 0.03 \mathrm{eV}(40 \pm 2 \mathrm{~kJ} / \mathrm{mol})$.

\section{Fracture Data}

When the crystals fractured about $80 \%$ of them did so on a plane perpendicular to the tensile axis and very often at a point close to one of the end grips. The nominal stress applied to the crystal, that is, the load applied divided by the original cross-sectional area of the crystal rather than the resolved shear stress, was found to be the influencing factor. Tables II and III show results for different crystals with different values of $\theta$, the angle between the tensile and optic axes. At $-50^{\circ} \mathrm{C}$ large strains were only obtained when the nominal stress on the crystal was about 8 bar; if this stress was around 12 bar, fracture occurred within 20-30 h, after straining approximately $\mathrm{I} \%$.

\begin{tabular}{|c|c|c|c|c|c|c|}
\hline Temperature & Crystal & $\theta$ & $\begin{array}{c}\text { Nominal } \\
\text { stress }\end{array}$ & $\begin{array}{l}\text { Time to } \\
\text { fracture }\end{array}$ & $\begin{array}{l}\text { Nominal strain } \\
\text { at fracture }\end{array}$ & $\begin{array}{c}\text { Tensile stress } \\
\text { at fracture }\end{array}$ \\
\hline${ }^{\circ} \mathrm{C}$ & & & bar & $\mathrm{h}$ & $\%$ & bar \\
\hline \multirow{10}{*}{$-5^{0}$} & VC & 65 & 12.0 & 10 & small & 12.0 \\
\hline & VIIA & 9 & 12.3 & 80 & I. 3 & 12.3 \\
\hline & VIA & 46 & $7 \cdot 9$ & 60 & 20.2 & $9 \cdot 5$ \\
\hline & IIIB & 68 & 12.4 & 55 & 5 & 12.8 \\
\hline & IIIA & 50 & 8.7 & 70 & 40 & 12.1 \\
\hline & IVB & 63 & 12.6 & 17 & small & I 2.6 \\
\hline & IIB & 68 & 10.7 & 50 & I. 6 & 10.8 \\
\hline & VA & $5^{2}$ & I 5.8 & 2 & 0.1 & I 5.8 \\
\hline & IVC & 64 & 9.9 & 40 & 6 & 10.2 \\
\hline & $\mathrm{XIC}$ & 63 & $9 \cdot 7$ & I 10 & $4^{0}$ & I 3.6 \\
\hline \multirow[t]{9}{*}{$-6 o$} & VIB & 50 & 16.4 & 17 & small & I6.1 \\
\hline & IIC & $6_{3}$ & I 7.6 & I 70 & 4 & I 8.0 \\
\hline & $\mathrm{XC}$ & $6 \mathrm{I}$ & 16.5 & 17 & small & 16.5 \\
\hline & XIID & 66 & 18.1 & 17 & small & 18. I \\
\hline & XIIE & 62 & $9 \cdot 3$ & I0o & 10 & 10.2 \\
\hline & XVIAI & 67 & I 2.1 & IIO & 1.5 & 12.3 \\
\hline & XVIA2 & 67 & I 7.2 & 25 & 1.2 & I 7.4 \\
\hline & XVIC & 64 & I3.0 & 80 & I. 3 & I3.I \\
\hline & XVIB & 62 & 14.8 & $4^{8}$ & I. & 14.9 \\
\hline
\end{tabular}

For very short times, however, a crystal could sustain larger stresses, for example, crystal VA which existed under a stress of 16 bar for $2 \mathrm{~h}$. The last column of Table II shows the tensile stress at the moment of fracture, assuming a uniform deformation. Since it is known that the crystals do not deform uniformly - they normally form a "tape" or "neck" - this column can only give a lower limit for the true tensile stress at the moment of fracture. Thus the actual tensile stress acting at the tape of crystal VIA after it had strained overall by $20 \%$ may well have been much larger than 9.5 bar.

At lower temperatures the fracture stress increased as can be seen from Tables II, III and IV. Although this increase in fracture stress was a help in obtaining a measurable deformation at the lower temperatures, it was not a large enough increase to compensate entirely for the loss of ductility at these temperatures. 
Table III. Fracture Data at $-70^{\circ},-80^{\circ}$ and $-90^{\circ} \mathrm{C}$

$\begin{array}{ccccccc}\begin{array}{c}\text { Temperature } \\ { }^{\circ} \mathrm{C}\end{array} & \text { Crystal } & \theta & \begin{array}{c}\text { Nominal } \\ \text { stress } \\ \text { bar }\end{array} & \begin{array}{c}\text { Time to } \\ \text { fracture } \\ \mathrm{h}\end{array} & \begin{array}{c}\text { Nominal strain } \\ \text { at fracture }\end{array} & \begin{array}{c}\text { Tensile stress } \\ \text { at fracture } \\ \text { bar }\end{array} \\ -70 & \text { VIA } & 50 & 16.7 & 24 & 0.3 & 16.7 \\ & \text { IXB } & 64 & 15.7 & 240 & 2 & 16.0 \\ & \text { XIA } & 44 & 13.5 & 104 & 5 & 13.8 \\ & \text { XVIIAI } & 60 & 18.6 & 144 & 2 & 18.9 \\ & \text { XVIIA2 } & 58 & 16.3 & 25 & 0.1 & 16.3 \\ & \text { XVIIC } & 45 & 16.5 & 24 & \text { small } & 16.5 \\ & \text { XVIID } & 46 & 13.6 & 120 & 5 & 14.3 \\ -80 & \text { XIXD } & 50 & 30.8 & 40 & 1.0 & 31.1 \\ -90 & \text { XXA } & 62 & 27.1 & 20 & 0.3 & 27.2 \\ & \text { XB } & 41 & 21 & 30 & \text { small } & 21.0 \\ & \text { XXC } & 40 & 35.5 & 40 & 0 & 35.5 \\ & \text { XXD } & 55 & 31.7 & 0 & 0 & 28.9\end{array}$

Table IV. Summary of Fracture Data

$\begin{array}{cc}\text { Temperature } & \begin{array}{c}\text { Mean tensile stress } \\ \text { at fracture }\end{array} \\ { }^{\circ} \mathrm{C} & \mathrm{bar} \\ -50 & 12.5 \pm 0.6 \\ -60 & 15.2 \pm 0.9 \\ -70 & 19 \pm 1 \\ -80 & 21 \text { (one specimen }) \\ -90 & 32 \pm 2\end{array}$

\section{Constant Strain-Rate Tests}

The apparatus and the method of using it have been described by Jones and Glen (1968). Cylindrical single crystals of ice, $1.5 \mathrm{~cm}$ in diameter and $3 \mathrm{~cm}$ in length, were compressed at a constant speed and stress-strain curves were recorded. The angle between the optic and tensile axes of the crystals was always close to $45^{\circ}$. Various temperatures were used in the experiment but only one nominal strain-rate, namely $2.7 \times 10^{-7} \mathrm{~s}^{-1}$.

Typical stress-strain curves obtained in the compression tests are shown in Figure 7 , for various temperatures, as marked on the curves. In general, as can be seen from this figure, no work hardening occurred during the deformation after the yield stress was passed-the stress

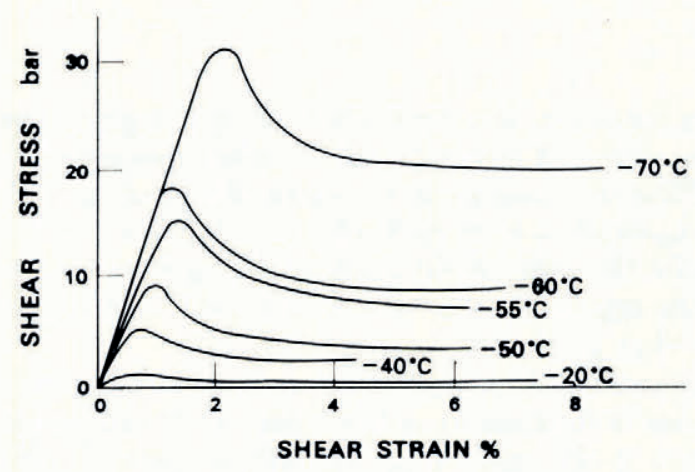

Fig. 7. Stress-strain curves of pure ice single crystals obtained at strain-rate of $2.7 \times 10^{-7} \mathrm{~s}^{-1}$, and at various temperatures. 
continued to drop at a decreasing rate even to the quite large strains (resolved shear strains of $10 \%$ ) observed in the experiment. In one test at $-70^{\circ} \mathrm{C}$, however, when resolved shear strains of up to $18 \%$ were observed, the stress did start to rise again at a strain of $15 \%$ as shown in Figure 8. This might have been a genuine work-hardening effect or it might possibly have been due to distortion of the crystal at large strains. It was only observed in the one test, but this was also the only test that continued to such large strains, because at the strain-rate used 4 days were needed to obtain a strain of $18 \%$.

The effects of temperature and of annealing on the stress-strain curves were analysed in detail by Jones and Glen (I968).

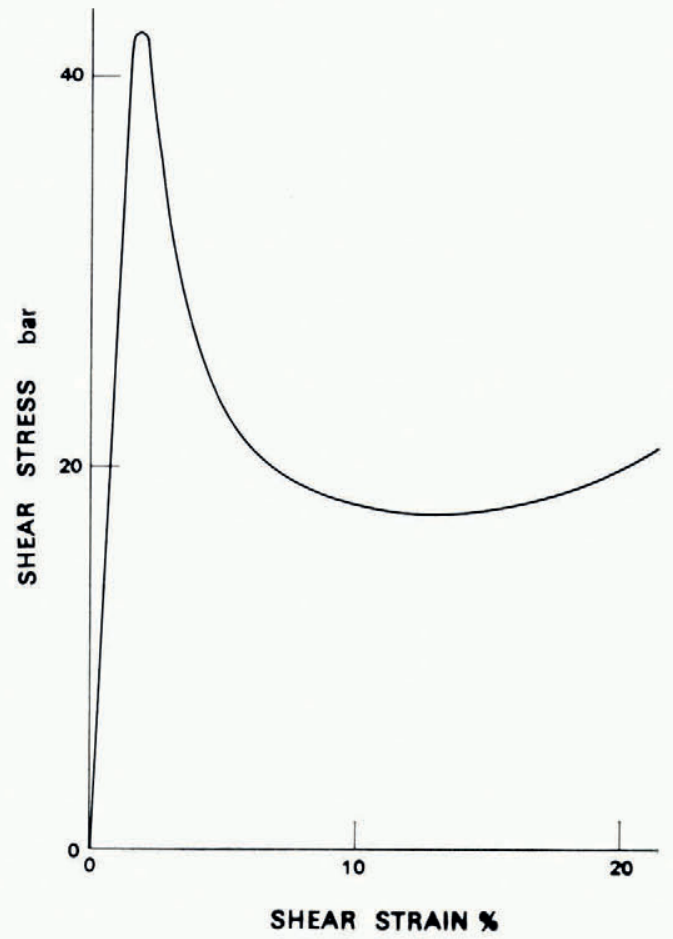

Fig. 8. Stress-strain curve of a crystal deformed at $-70^{\circ} \mathrm{C}$, showing an increase in stress at a strain of about $13 \%$.

\section{Computed Stress-strain Curves}

It was decided to analyse the stress-strain curves obtained in this experiment along the lines of Johnston's (1962) theory developed for lithium fluoride. A brief reference to some results of this analysis was made by Jones and Glen (1968).

$\mathrm{LiF}$ has a stress-strain curve like that of ice in that it has an upper yield stress followed by a yield drop. It differs from ice in that at moderate strains, about $\mathrm{I}-2 \%$, work hardening becomes very marked. This is not of importance in applying the theory to ice because the initial theory was formulated for the case of no work hardening and an extra term, which can be neglected for ice, was added later to take work hardening into account. Johnston (1962) was able to use the experimentally known behaviour of dislocations in LiF, as determined by etch pit methods, to compute stress-strain curves which fitted the experimental ones satisfactorily. 
The strain-rate $\dot{\epsilon}$ of a deforming crystal was given by Cottrell (1953) as

$$
\dot{\boldsymbol{\epsilon}}=b \gamma(\boldsymbol{\epsilon}) v(\tau)
$$

where $b$ is the Burgers vector of the dislocations, $\gamma(\epsilon)$ is the density of dislocations, which is a function of the strain, and $v(\tau)$ is the dislocation velocity which, at a constant temperature, is a function of stress. If only pure edge and pure screw dislocations are present in the crystal, and they move with different velocities, Equation (4) must be rewritten as

$$
\dot{\epsilon}=b\left(\gamma_{\mathrm{s}} v_{\mathrm{s}}+\gamma_{\mathrm{e}} v_{\mathrm{e}}\right)
$$

where the suffix s refers to screw dislocation and the suffix e to edge dislocation. Johnston considered the case when $v_{\mathrm{s}} \ll v_{\mathrm{e}}$, as in $\mathrm{LiF}$, and showed that Equation (3) can be simplified to

$$
\dot{\epsilon}=2 b \gamma v_{\mathrm{s}} \text {. }
$$

In $\mathrm{LiF}$, the dislocation density increases linearly with strain so that with

$$
\gamma=\alpha \epsilon
$$

with $\gamma=\mathrm{IO}^{13}$ dislocations $/ \mathrm{m}^{2}$, and the dislocation velocity is given by

$$
v_{\mathrm{s}}=(\tau / D)^{p}
$$

where $D=0.53$ bar and $p=16.5$. Thus the strain-rate is given by

$$
\dot{\epsilon}=2 b \alpha \epsilon(\tau / D)^{p} \text {. }
$$

An experimental stress-strain curve is obtained by causing a specimen to interact with a testing machine. The crosshead moves at a constant speed, $S_{\mathrm{c}}$, so as to compress the crystal against an anvil. Part of the crosshead motion goes into the elastic strain of the deforming fixture and crystal, which can be thought of as an imaginary spring of force constant, $K$. The elastic displacement is $\Delta y_{\mathrm{el}}=F / K$ where $F$ is the applied force. If $\Delta L_{\mathrm{p}}$ is the amount of plastic deformation of the crystal, the total crosshead displacement is

$$
\Delta y=S_{\mathrm{c}} t=\Delta y_{\mathrm{el}}+\Delta L_{\mathrm{p}}
$$

where $t$ is the time. The plastic strain is

$$
\epsilon=\frac{\Delta L_{\mathrm{p}}}{L_{\mathrm{o}}}=\left(S_{\mathrm{c}} t-F / K\right) / L_{\mathrm{o}}
$$

The plastic strain-rate is therefore

$$
\dot{\epsilon}=\left(S_{\mathrm{c}}-K^{-\mathrm{I}} \mathrm{d} F / \mathrm{d} t\right) / L_{0} .
$$

By converting the variables $F$ and $t$ to resolved shear stress $\tau$ and crosshead displacement $y$ respectively, and substituting Equations (I I) and (I2) into (9) the equation

$$
\frac{\mathrm{d} \tau}{\mathrm{d} y}=C-B(\tau / D) p(C y-\tau)
$$

is obtained. $C$ is given by $K / 2 A, B=2 b \alpha / S_{\mathrm{c}}$, and $\tau=F / 2 A$ where $A$ is the cross-sectional area of the specimen. Equation (1 3 ) is a reformulation of the strain-rate equation (5) incorporating the assumptions mentioned. For an initial pair of values $\left(\tau_{0}, y_{0}\right)$ which is equivalent to specifying $\left(\tau_{0}, \gamma_{0}\right)$ where $\gamma_{0}$ is the initial number of mobile dislocation present in the crystal, the differential equation can, in principle, be integrated to obtain the stress-strain curve that the testing machine should produce under the same initial conditions. This is what Johnston did and he obtained good agreement with LiF stress-strain curves determined experimentally.

Unfortunately, we do not know how the individual dislocations in ice respond to stress, as no suitable etchant has been discovered which will show the basal dislocations. In other words, we do not know whether Equations (7) and (8) are valid for ice. It was decided to fit Equation (12) to the ice data, varying the parameters, until good agreement was obtained, in the hope of obtaining some useful information about the dislocations in ice. Therefore, Equations (7) and (8) were assumed to hold for ice and the effect of varying the parameters 
$\alpha, D, \gamma_{0}$ and $p$ for known $K$, the stiffness of the machine, and $S_{\mathrm{c}}$, the speed of compression was observed. Of these four parameters $p$ is the best known since it should determine the stress dependence of the strain-rate of the crystals, and should therefore equal $n$ of Equation (2). The effect of varying $D$ is only to alter the scale of the stress-strain curve and does not alter the shape of the curve. The parameters $\gamma_{0}$ and $\alpha$ are least known for ice. It was assumed that

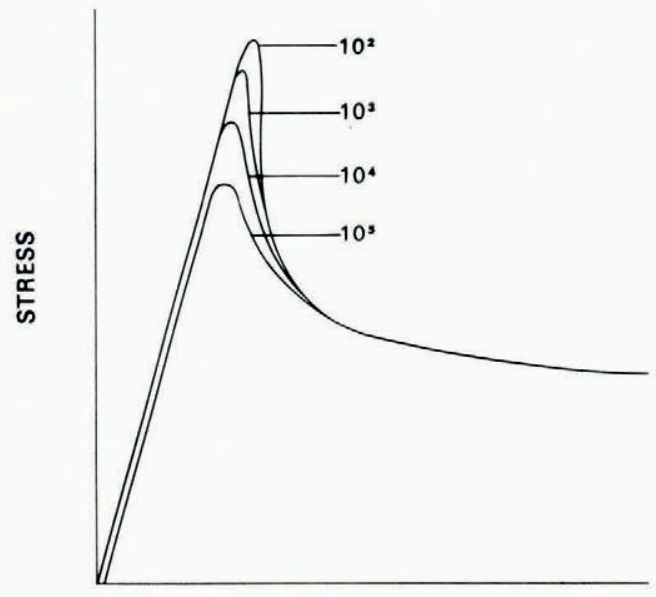

STRAIN

Fig. 9. The effect of varying $\gamma_{0}$, the initial number of dislocations, on the computed stress-strain curves.

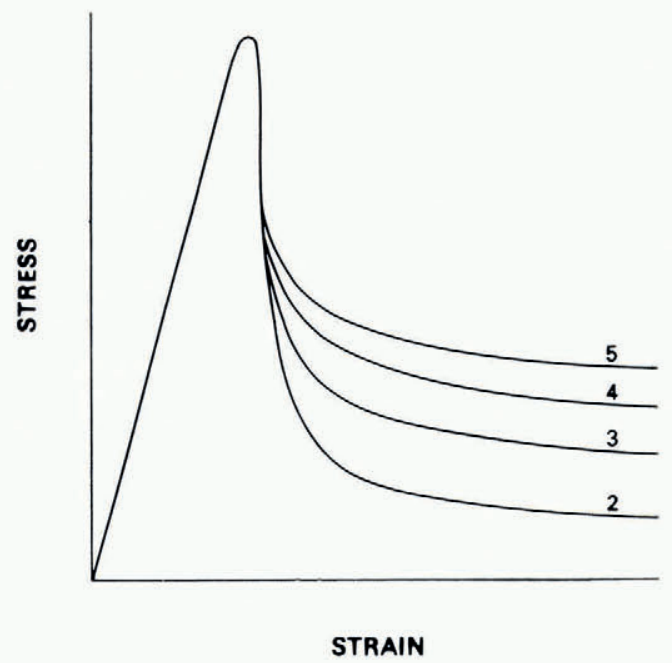

Fig. 10. The effect of varying $p$, of Equation (8), on the computed stress-strain curves. The upper yield stress is kept constant by adjusting $D$.

$\alpha=\mathrm{IO}^{13} / \mathrm{m}^{2}$ (as in $\mathrm{LiF}$ ) and it was found that varying $\alpha$, like varying $D$, did not alter the shape of the curve.

The effects of varying $\gamma_{0}$ and $p$ are shown in Figures 9 and io. Varying $\gamma_{0}$, keeping all the other parameters fixed, changes the upper yield stress but above all it alters the width of the peak. The effect of varying $p$, on the other hand, is to alter the yield drop, as seen from Figure 10 , in which $D$ has also been changed to keep the upper yield stress constant. Varying 
$p$ does not alter the width of the curve, so that once the correct width of the computed curve has been obtained by varying $\gamma_{0}, p$ can be varied to give the correct yield drop and $D$ can be altered to give the correct upper yield stress.

Such a fit is shown in Figure $\mathrm{I}$, in which the solid line is the computed curve and the open circles are experimental points for two crystals deformed at $-50^{\circ} \mathrm{C}$. The parameters used to fit the curve were $p=3.0, D=\mathrm{I}$ ooo bar and $\gamma_{0}=5 \times 10^{9}$ dislocations $/ \mathrm{m}^{2}$. The value of $p$ is in reasonable agreement with the value expected from the stress dependence of the strain-rate of the tensile creep experiment. The number of initial mobile dislocations is a lot higher than that found by Johnston in $\operatorname{LiF}\left(c .10^{7}\right)$, but it may be a reasonable value for the method used to grow the crystals. The value of $D$ gives a dislocation velocity of $1.7 \times 10^{-8}$

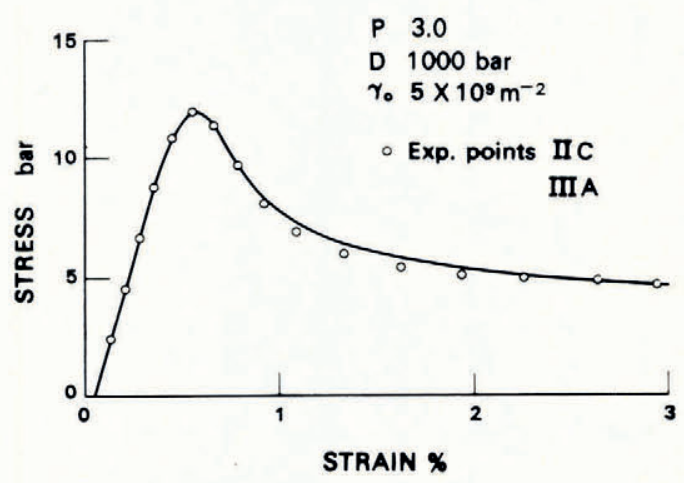

Fig. II. A computed stress-strain curve (solid line) compared with the experimental points of two crystals deformed at $-50^{\circ} \mathrm{C}$.

$\mathrm{m} \mathrm{s}^{-1}$ at the upper yield point, dropping to $0.2 \mathrm{I} \times 10^{-8} \mathrm{~m} \mathrm{~s}^{-1}$ by the time the stress has fallen to 6 bar. It is not surprising that the velocities are small since the strain-rate used was only $2.7 \times 10^{-7} \mathrm{~s}^{-1}$. An explanation of this low dislocation velocity has been given by Glen (1968) based on the re-orientation of hydrogen bonds in ice.

Recent work by Fukuda and Higashi (rg69), using an X-ray topographical technique, has given a dislocation velocity of $1 \mathrm{O}^{-5} \mathrm{~m} \mathrm{~s}^{-1}$ at $-22^{\circ} \mathrm{C}$. With an activation energy of $0.68 \mathrm{eV}$, as measured in the present paper, a velocity of $2 \times 10^{-7} \mathrm{~m} \mathrm{~s}^{-1}$ at $-50^{\circ} \mathrm{C}$ is computed from their value. It is difficult to know exactly the value of the stress acting on Fukuda and Higashi's dislocations, since their experiments were conducted in bending, but they quoted a value of $\mathrm{roo}$ bar, in which case their experimental value is in reasonable agreement with the value deduced in these calculations.

\section{AcKnowledgements}

We should like to thank the Royal Society for the provision of the cold laboratory used in the preparation and handling of specimens, and the Science Research Council for a research studentship held by one of us (S.J.J.). 


\section{REFERENGES}

Cottrell, A. H. 1953. Dislocations and plastic flow in crystals. Oxford, Clarendon Press.

Fukuda, A., and Higashi, A. 1969. X-ray diffraction topographic studies of the deformation behaviour of ice single crystals. (In Riehl, N., and others, ed. Physics of ice: proceedings of the international symposium on physics of ice, Munich, Germany, September 9-14, I968. Edited by N. Riehl, B. Bullemer, H. Engelhardt. New York, Plenum Press, p. $239-50$.

Glen, J. W. 1968. The effect of hydrogen disorder on dislocation movement and plastic deformation of ice. Physik der kondensierten Materie, Bd. 7, Ht. I, p. 43-5I.

Glen, J. W., and Jones, S. J. 1967. The deformation of ice single crystals at low temperatures. (In Oura, H., ed. Physics of snow and ice: international conference on low temperature science. . . . 1966. . . Proceedings, Vol. I, Pt. I. [Sapporo], Institute of Low Temperature Science, Hokkaido University, p. 267-75.)

Hayes, C. E., and Webb, W. W. 1965. Dislocation in ice. Science, Vol. 147, No. 3653, p. 44-45.

Higashi, A., and others. 1965 . Bending creep of ice single crystals, [by] A. Higashi, S. Koinuma and S. Mae. Japanese Journal of Applied Physics, Vol. 4, No. 8, p. 575-82.

Johnston, W. G. I962. Yield points and delay times in single crystals. Fournal of Applied Physics, Vol. 33, No. 9, p. 2716-30.

Jones, S. J., and Glen, J. W. 1968. The mechanical properties of single crystals of ice at low temperatures. Union de Géodésie et Géophysique Internationale. Association Internationale d'Hydrologie Scientifique. Assemblée générale de Berne, 25 sept.-7 oct. 1967 . [Commission de Neiges et Glaces.] Rapports et discussions, p. 326-40.

Jones, S. J., and Glen, J. W. 1969 . The effect of dissolved impurities on the mechanical properties of ice crystals. Philosophical Magazine, Eighth Ser., Vol. 19, No. 157, p. I3-24.

Readey, D. W., and Kingery, W. D. 1964. Plastic deformation of single crystal ice. Acta Metallurgica, Vol. 12, No. 2, p. $171-78$.

Schmid, E., and Boas, W. 1950. Plasticity of crystals. London, F. A. Hughes and Co.

Worthing, A. G., and Geffner, J. [1943.] Treatment of experimental data. New York, John Wiley and Sons, Inc. 